Sitientibus Série Ciências Físicas 04: 1-10 (2008)

\title{
Obstáculos Epistemológicos e o Conceito de Calor
}

\author{
Epistemological Obstacles and the Concept of Heat
}

\author{
Jornandes Jesús Correia* e Ludiane Silva Lima \\ Departamento de Ciências Exatas - UESB \\ Estrada do Bem Querer, Km 04, Candeias \\ Vitória da Conquista - BA - 45083-900 \\ Lívia Diana Rocha Magalhães \\ Departamento de Filosofia e Ciências Humanas - UESB \\ Estrada do Bem Querer, Km 04, Recreio \\ Vitória da Conquista - BA - 45083-900
}

\begin{abstract}
A cultura científica contribuiu para o surgimento de obstáculos epistemológicos devido ao uso de expressões como "Geração", "Transferência", "Troca", "Perda", "Retirada", "Corrente", "Propagação", "Condução", "Escoamento", "Irradiação" e "Fluxo" de Calor. Com isso, erros conceituais são inseridos na definição de calor, o que compromete a compreensão dessa grandeza física. Os livros didáticos, que são indispensáveis ao aprendizado e à difusão do conhecimento, têm contribuído para disseminar e vulgarizar expressões inadequadas em suas definições, atribuindo características substancialistas ao calor. A cultura científica baseada na aceitação do calórico, e apoiada no prestígio de cientistas como Fahrenheit, Carnot, Galileu, Lavoisier, Laplace, Fourier, Kelvin e Black, foi gradualmente dando lugar a uma nova definição do calor. Foi necessário que outra plêiade de cientistas desmistificasse o calórico e atribuisse um novo significado ao calor. Entretanto, o uso contínuo de termos remanescentes à época em que a teoria do calórico era aceita, denominações como Calor Latente, Calor Sensível e Condutibilidade Térmica etc., têm se constituído como verdadeiros obstáculos na mudança conceitual do calor. Nessa perspectiva, este trabalho tem como objetivo analisar o conceito de calor, verificando a existência de obstáculos epistemológicos causados pela imprecisão do seu uso.
\end{abstract}

Palavras-chaves: Obstáculo Epistemológico, Energia, Calor, Calórico, Cultura Científica.

The scientific culture has contributed for the appearance of epistemological obstacles due to the use of expressions such as "Generation", "Transference", "Exchange", "Loss", "Removal", "Current", "Propagation", "Conduction", "Flow", "Irradiation" and "Flux" of heat. So, conceptual mistakes are inserted in the definition of heat and has compromised the understanding of this physical quantity. The textbooks, which are indispensable for the learning and the spread of knowledge, has contributed to disseminate and to turn commonness inappropriate expressions to the definitions of physical quantities, so assigning characteristics as a substance to the heat. The scientific culture based on the acceptable of caloric, and support by the prestige of scientist such as Fahrenheit, Carnot, Galileo, Lavoisier, Laplace, Fourier, Kelvin e Black, was gradually given place to a new definition for the heat. It was necessary other pleiad of scientist to demystify the caloric and to assign a new meaning to the heat. However, the persistent usage of terms remnants to the time when the theory of caloric was acceptable, names as Latent Heat, Sensible Heat and Thermal Conductibility etc., has constituted real obstacles for the conceptual change of heat. In this perspective, this work has as objective to analyze the concept of heat and verifying the existence of epistemological obstacles due to the imprecision of its usage.

Key-words: Epistemological Obstacle, Energy, Heat, Caloric, Scientific Culture. 


\section{INTRODUÇÃO}

Encontra-se na literatura muitos trabalhos que tratam do calor, principalmente do ponto de vista histórico. Entre outros, Allard [1, 2] tratam da história da ciência de uma maneira geral e apresentam um breve histórico do calor. Wilson (1967) [3] trata da história da energia, também de modo geral, mas traz um resumo dos postulados do calórico. Bassalo (1986) [4] escreveu uma crônica do calor, tecendo um histórico da termometria. Bassalo (1992) [5] continua com a sua crônica do calor, em seu segundo artigo, apresentando um estudo histórico da calorimetria.

Do ponto de vista da epistemologia, constatamos também a existência de alguns trabalhos sobre o conceito de calor. Dentre outros, Axt e Brückmann (1989) [6] analisaram o conceito de calor em livros de $8^{\text {a }}$ Série e constataram que os livros não satisfazem aos requisitos do formalismo científico do calor. Costa e Hülsendeger (2004) [7] fizeram um levantamento da concepção que alunos do ensino médio e superior têm sobre o calor e atribuíram às dificuldades para a aplicação de formalismos matemáticos aos conhecimentos prévios dos alunos. Cindra e Teixeira (2004) [8] discutiram a categorização das explicações (heterogênea, homogênea e batígena) desenvolvidas por Halbwacs, relacionando-a com o desenvolvimento histórico do conceito de calor e temperatura, enquanto que Amaral e Mortimer (2001) [9] discutem uma proposta de perfil conceitual (realista, animista, substancialista, empírica e racionalista) para o calor.

Nesses trabalhos citados, a maioria deles discute sobre as concepções espontâneas que os estudantes apresentam sobre o calor, trazem um desenvolvimento histórico do calor, dificuldades de aprendizagem para apreender o conceito de calor, bem como dificuldades de aplicação de formalismos matemáticos para quantificar o calor.

Correia et al. (2008) [10] apresentaram um trabalho sobre o conceito de calor, sugerindo a existência de obstáculos epistemológicos, propuseram a superaração da idéia substancia- lista do calor e também uma definição para o calor como sendo uma energia térmica em trânsito. Amaral e Mortimer (2001) [9] embora tenham analisado as idéias relacionadas ao conceito de calor, à luz dos obstáculos epistemológicos, suas análises restringem-se à classificação dos obstáculos (substancialista, animista e de primeira experiência).

$\mathrm{Na}$ sala de aula, muitas definições inadequadas vão comparecendo quando determinados conteúdos são ministrados e passam a ser discutidos com os alunos. Pelo tipo de conhecimento apresentado pelos alunos sem a devida análise, tudo indica que vem sendo disseminado e provocado a repetição de incoerências ou inconsistências sobre o conteúdo estudado.

Neste trabalho pretendemos discutir como os obstáculos epistemológicos dificultam o entendimento da teoria do calor e apontamos que a cultura científica tem contribuído para que "calor" ainda seja definido com propriedade fluídica.

\section{OBSTÁCULOS EPISTEMOLÓGICOS}

Trataremos a seguir do significado de "obstáculos epistemológicos", pois a compreensão desse termo é imprescindível para que o leitor atinja os objetivos propostos neste trabalho.

Como afirma Bachelard (1996) [11],

Quando se procuram as
condições psicológicas do pro-
gresso da ciência, logo se chega
à conviç̧ão de que é em termos
de obstáculos que o problema do
conhecimento científico deve ser
colocado (p. 17).

Sendo assim, o ato de conhecer sempre supõe superar conhecimentos que, de alguma forma, estejam dificultando o entendimento do real. Segundo Bachelard (1996) [11], os obstáculos epistemológicos são inerentes ao novo conhecimento, pois

$$
\begin{gathered}
\text { É no âmago do próprio ato } \\
\text { de conhecer que aparecem, por }
\end{gathered}
$$


espécie de imperativo funcional, lentidões e conflitos" ( $p$. 17).

Amaral e Mortimer (2001) [9] destacam que obstáculos epistemológicos podem

ser a causa da inércia e estagnação e até regressão na busca do conhecimento.

Andrade (2004) [12] conceitua Teoria, Conhecimento, Ciência e Obstáculos e argumenta sobre a importância dos obstáculos epistemológicos à ciência e aponta que o Espírito Cientifico é a via de suas superações. Quanto ao conceito de obstáculos a autora destaca:

Obstáculo proporciona, de imediato, a idéia de dificuldade, de força oposta ao que se tenta fazer, de contra-mão, de entrave, de limitação. Contudo, é importante ressaltar ao mesmo tempo, pode despertar um sentimento de superação, de transposição de limites, o que viabiliza a procura pelo conhecimento cientifico.

Valendo-se da definição de obstáculo contida no dicionário de Filosofia de Nicola Abbagnano, tem-se que obstáculo é "o limite de uma atividade". Neste mesmo diapasão, aponta-se a definição de Aurélio Buarque de Holanda, o qual apresenta como sinônimo de obstáculo "embaraço, impedimento, estorno, empecilho, barreira".

Desta forma, comprova que a idéia de obstáculo proposta por Bachelard, realmente, coaduna-se com dificuldades inerentes ao processo de busca pelo conhecimento cientifico.

Recorrendo ainda a Bachelard (1996) [11] diríamos que

Hábitos intelectuais que foram úteis e sadios podem, com o tempo, entravar a pesquisa ( $p$. 19).
É nessa perspectiva que passamos a problematizar um dos temas que tem invadido a nossa prática pedagógica no cotidiano da sala de aula: a imprecisão do conceito de calor.

À medida que íamos detectando esses problemas, passamos a eleger a pesquisa sobre os livros didáticos de física, particularmente os utilizados durante os quarenta últimos anos, e a rastrear, dentre outros conceitos, como a teoria sobre o calor vem sendo transmitida.

Nas nossas aulas, os alunos sempre recorrem às expressões matemáticas que fazem uso de Calor Latente ou Sensível com a certeza que não estão tratando do calor como uma substância. Mas, recorrem ao uso de grandezas próprias do corpo, como a sua massa, o Calor Latente de mudança de fase e suas diferenças de temperatura para definir, de forma imperceptível, o calor como uma propriedade do corpo, mesmo quando afirmam que o calor não poderia estar contido num corpo ou em um sistema. Percebemos ainda que as suas idéias conceituais destoam de suas próprias análises, quando fazem o uso de expressões matemáticas para calcular o calor. Além disso, há o uso de afirmações do senso comum, tal como "estou sentindo calor" que diverge completamente da designação científica do termo. Em síntese: temos observado que o conceito de calor é usado com certa imprecisão, quando é tomado por algo inerente ao corpo, quando deveria caracterizar uma energia que está em trânsito.

\section{O QUE É CALÓRICO}

Neste item apresentaremos um resumo histórico do calórico e os seus postulados, considerando que temos observado que os livros têm dado pouca importância à Teoria do Calórico e muito pouco tem sido encontrado sobre os seus postulados.

No século XVIII, a Teoria do Calórico, desenvolvida a partir de postulados essenciais, registrados em 1779 (WILSON, 1967 [3]), concebeu o calor como sendo uma substância fluida, que passa de um local para outro. Viam-na também como sendo invisível e indestrutível, 
como pode ser observado na citação abaixo:

O calórico é um fluido elástico e suas partículas se repelem mutuamente;

As partículas do calórico são atraidas fortemente pelas formas de matéria e estas atraem as partículas do calórico com intensidades diferentes;

O calórico é indestrutivel, ele não pode ser criado;

O calórico pode ser sensivel ou latente (sentido ou armazenado respectivamente), onde no estado latente seria combinado "quimicamente" com partículas da matéria para mudar de sólido para líquido ou se líquido em vapor.

Sabe-se que até o inicio do século XIX, os cientistas acreditavam que essa substância fluida, invisível e imponderável existia no interior dos corpos, de forma tal que quanto maior fosse a quantidade de calórico, maior seria a sua temperatura. De acordo com essas idéias, quando dois corpos com temperaturas diferentes eram colocados em contato, haveria passagem de calórico do mais quente para o mais frio. Essa passagem seria interrompida quando as temperaturas dos dois corpos se igualassem, isto é, quando atingissem o equilíbrio térmico.

\section{DO CALÓRICO AO CALOR}

Trataremos neste item da transição da teoria do calórico para a concepção de calor aceita atualmente.

Os postulados do calórico foram questionados por Rumford, que passou a perguntar o que era calor, ao meditar sobre suas observações feitas na oficina em que trabalhava quando ele estava supervisionando a perfuração de um artefato metálico. Eis o relato de Rumford, quando propôs derrubar a teoria do calórico:

Foi por acaso que me vi levado a realizar as experiências que vou relatar agora... Estando ocupado, ultimamente, em supervisionar a perfuração de canhões nas oficinas do arsenal militar de Munique, chamou-me a atenção o elevado grau de aquecimento de um canhão de bronze, atingido em tempos muito curtos, durante o processo de perfuração; bem como a temperatura ainda mais alta (acima do ponto de ebulição da água, conforme verifiquei) das aparas metálicas removidas pela perfuração.

Meditando sobre os resultados dessas experiências, somos naturalmente levados à grande questão que tem sido objeto de tantas especulações filosóficas, ou seja:

Que é calor? Existe um fluido igneo? Existe alguma coisa que possamos chamar de calórico?

Vimos que uma quantidade muito grande de calor pode ser produzida pelo atrito de duas superfícies metálicas, e emitida num fluxo constante em todas as direções, sem interrupção, e sem qualquer sinal de diminuição ou exaustão...

... a fonte de calor gerada por atrito nessas experiências parece ser inesgotável. É desnecessário acrescentar que algo que qualquer corpo ou sistema de corpos isolado pode continuar fornecendo sem limites, não pode ser uma substância material, e me parece extremamente difícil, senão impossivel, conceber qualquer coisa capaz de ser produzida ou transmitida da forma como o calor o era nessas experiências exceto o "MOVIMENTO".

Outro cientista que contribuiu para o avanço nas pesquisas sobre calor e também da Termodinâmica foi J. Robert Mayer (1814-1878). Para ele o calor era uma forma de energia, po- 
dendo transformar-se em qualquer outra forma de energia. Mayer chegou a propor a conservação da energia térmica, porém as suas idéias não foram aceitas na época. Coube a John Tyndall (1820-1893) o esforço para que a descoberta da lei da conservação da energia, para a Termodinâmica, fosse creditada a Mayer.

\section{O CALOR E OBSTÁCULOS EPISTEMOLÓGICOS}

Quando é perguntado, por exemplo, o que é calor, quase sempre são obtidas respostas que atribuem ao calor qualidades substancialistas. Máximo e Alvarenga (1997, p. 590) [13], responde a esta pergunta da seguinte forma: "Calor é a energia transferida de um corpo para outro em virtude unicamente de uma diferença de temperatura entre eles". Nesta citação, percebemos certa ambigüidade, pois afirma que o termo calor não pode estar contido no corpo, mas este pode ser transferido de um corpo para outro. Ora, se algo foi transferido de um lugar para outro é por que esse algo já existia naquele lugar de origem. Compreendemos que o termo "calor" só deveria ser utilizado para designar uma energia que se encontra em transferência entre corpos, desde que exista entre eles uma diferença de temperatura.

Pesquisas realizadas sobre o calor como a de Brückmann e Axt (1989) [6] originou o artigo intitulado "O conceito de Calor nos livros de ciências", em que os autores fizeram uma comparação de textos de seis livros diferentes de Química e Física da $8^{\mathrm{a}}$ série, para discutir os atributos que caracterizariam uma conceituação formal do termo. Observamos que tanto eles como outros autores, como Cindra e Teixeira (2004) [8] e Bassalo (1992) [5], tanto analisam historicamente a forma como o conceito foi sendo utilizado, como também usam as equações (fórmulas) para quantificar essa grandeza, defendendo a tese de que calor é uma "energia que não pode estar localizada num corpo". No entanto, é interessante observar que a definição de calor continua, de forma im- perceptível, recebendo qualidades substancialistas. Então, passamos a considerar que há um "obstáculo epistemológico" que, do ponto de vista normativo, possivelmente esteja baseado em uma "cultura científica" que usa o conceito de calor, com base na teoria do calórico, uma vez que o calor era considerado como um fluido imponderável que poderia ser adicionado ou retirado do corpo.

E assim, passamos a constatar que há um tratamento inadequado na teoria do calor e passamos a considerar que o maior obstáculo encontrado está nesta imprecisão. Acreditamos que a mesma palavra calor

\section{[...] tanto designa quanto ex- plica. A designação é a mesma (Bachelard, p. 22 [11]).}

Mas na verdade, em nossa opinião, a explicação sobre o que venha a ser calor deveria ser diferente.

Ora, será que a didatização do termo para expressar um simples fato corriqueiro do diaa-dia, como o ato de aquecer algo, passou a ser utilizado a partir de uma linguagem direta, compreensível, evitando assim, a linguagem cientifica? Ou estaria embutida aí, a comodidade de manter "[..]um elemento de solidez e de confiança" a um conceito científico que foi capaz de expressar as primeiras imagens do fenômeno?

É interessante observar que os pressupostos da teoria do calórico, que supõe que o calor é do próprio do corpo, continuam bastante vigentes. Se retomármos exemplos ou afirmações comuns aos livros pesquisados, poderíamos observar que há referência ao calor como algo que está sendo liberado, absorvido ou em estado potencial. Se algo está sendo liberado é porque o mesmo estava em algum lugar. Portanto, entendemos que o termo "energia térmica" é que deveria ser usado para designar a energia associada ao movimento das moléculas, pois é devido ao seu grau de aquecimento e que de fato é própria do corpo. Uma vez que a energia envolvida é proveniente de um outro lugar (ou sistema) e está envolvida com uma variação de temperatura desse ou do outro corpo (ou sistema), essa energia pode ser transferida. 
Imprecisões conceituais ainda persistem em muitos livros e em sistematizações científicas, quando trata da conceituação de calor. Tudo indica que muitos autores, principalmente de livros didáticos, instintivamente ainda se baseiam tanto quantitativa quanto qualitativamente nos postulados do calórico.

Neste sentido, surgem pelos menos dois questionamentos: por que a utilização do termo calor está quase sempre associada a uma característica de um fluido? E então, para que e como deveríamos designar o termo?

\section{DEFINIÇÃO DE CALOR NOS LIVROS DIDÁTICOS}

$\mathrm{Na}$ seção seguinte discutiremos como a definição do calor é apresentada nos livros didáticos nos níveis de ensino médio e superior.

Máximo e Alvarenga (1997) [13] afirmam que se um

“... corpo é colocado em contato com outro, de temperatura mais baixa, haverá transferência de energia do primeiro para o segundo, energia esta denominada calor" (p. 590).

Do ponto de vista da análise conceitual podemos afirmar que em vários trechos desse livro existem vestígios da teoria do calórico na concepção do que seja calor, uma vez que na transferência de algo de um corpo para outro significa dizer que este que foi transferido estava contido no lugar de origem. Entretanto, na página 589 dessa mesma obra, os autores fazem um breve relato da teoria do calórico. Para um leitor criterioso, estas contradições podem significar uma problematização de algo que poderia ser discutido em sala de aula, enquanto que para outros essa representação pode caracterizar um empecilho para a contextualização de outros conteúdos que necessitam do entendimento do conceito do calor.

Máximo e Alvarenga (1997) [13] apresentam uma figura (p. 590) que ilustra, de forma muito clara, a idéia do calor. Nessa figura os autores representam dois sistemas: o sistema 1 , a uma temperatura $T_{1}$; e o sistema 2 a outra temperatura $T_{2}$. Inicialmente foi afirmado que $T_{1}$ é maior que $T_{2}$. Na interação do sistema 1 com o sistema 2 há transferência de energia do primeiro sistema para o segundo, energia essa denominada "calor" pelos autores. Devido a essa transferência de energia, a energia interna do sistema 1 diminui enquanto que a energia interna do sistema 2 aumenta, até atingir o equilíbrio térmico.

Embora Máximo e Alvarenga (1997) [13] tenham feito uma discussão muito rica sobre o calor, distinguindo-o de energia interna, eles ainda afirmaram:

"É importante observar,
ainda, que a energia interna de
um corpo pode aumentar sem
que o corpo receba calor (grifo
nosso), desde que ele receba al-
guma outra forma de energia" ( $p$.
590).

Essa ambiguidade de mostrar oposição à teoria do calor aceita no século XVIII, e de forma imperceptível retomar essa teoria, está presente em toda a sua obra nos capítulos relacionados ao calor.

GONÇALVES e TOSCANO (1997) [14], por exemplo, definem o calor como o processo de transferência da energia térmica de um corpo para outro. Vale a pena destacar que o "calor" não é um processo e sim uma energia em estado de transferência.

Vários livros pesquisados, tais como GONÇALVES (1979) [15], CALÇADA e SAMPAIO (1998) [16], PARANA (1998) [17], dentre outros, utilizaram em diversas situações termos como receber, ceder e trocar calor, confirmando a nossa tese de que o calor é empregado, mesmo que de forma imperceptível, com as concepções de calórico.

A simples troca da palavra calor por energia térmica poderia dizimar essa contradição, quando na definição de calor estiver envolvendo expressões como "transferência de calor de um corpo para outro". Embora não seja tão elementar efetuar essas substituições, esforços 
nesse sentido deixariam as definições mais coerentes, uma vez que a energia térmica pode ser transferida de um corpo para outro, sendo esta uma qualidade do corpo.

A Concepção substancialista do calor foi também detectada nos seguintes livros didáticos: ALONSO e FINN (1972) [18], BONJORNO (1985) [19], CHIQUETTO e PARADA (1986) [20], COSTA (1971) [21, 22], GIUDICE NETO (1980) [23], GOLDEMBERG (1970) [24], GREF (2005) [25], HALLIDAY (1977) [26], MACEDO (1976) [27], MORETTO (1982) [28], NUSSENZVEIG (2004) [29], OLIVEIRA (2005) [30], OREAR (1976) [31], PÁDUA (2006) [32], RAMALHO JR. (1986) [33], RAMALHO JR. (1993) [34], SANTOS (1986) [35], SEARS (1966) [36], SEARS e SALINGER (1979) [37], SEARS e ZEMANSKY (1976) [38], TIPLER (1978) [39], TOLEDO SOARES (1984) [40], UENO e YAMAMOTO (1982) [41], WYLEN (1973) [42] e ZEMANSKY (1978) [43].

\section{DISCUSSÃO}

Se retomarmos ao final do item 5 poderemos observar que para a segunda pergunta ser respondida deve-se saber distinguir calor de energia térmica. A energia térmica é uma energia que se transfere de um corpo para outro. Seria desnecessário citar que tal transferência é devida a uma diferença de temperatura. Definir calor como energia transferida pode dar origem a um grande problema, pois existem várias situações práticas em que parte dessa energia, devido à diferença de temperatura, tenha se transformado em outra forma de energia como, por exemplo, o Trabalho.

Então, como resolver essa situação? A resposta surge quando o termo "energia térmica" puder ser utilizado em situações em que o termo calor não apresentar coerência. Nesse sentido, o emprego do termo "energia térmica" em lugar do termo "calor" contribui para solucionar o problema da transformação de uma energia em outra tanto antes como após o processo de transferência.
Um outro problema é ter clareza do que venha a ser Energia. Esse é um outro conceito que merece destaque, pois está entre os mais importantes da ciência, uma vez que é uma grandeza física inerente a todo fenômeno científico. Definir uma grandeza, a sua variação ou a sua transformação requer sutilezas que nem sempre são utilizadas de forma adequada.

Torna-se muito mais conveniente denominála, equacioná-la ou calculá-la. Sob a nossa óptica, o conceito de calor se encaixa perfeitamente na categoria batígena (Cindra e Teixeira, 2004, [8]), pois para conceituá-lo lança-se mão de outros termos com o seu mesmo nível de complexidade. Para respaldar o nosso ponto de vista, foi feito um estudo da história e da evolução do conceito do calor. Nesse estudo constatamos a existência de obstáculos epistemológicos associados à cultura científica devido, principalmente, ao prestígio de cientistas que defenderam uma concepção substancialista do calor contrária à concepção conceitual aceita atualmente.

Agora o problema é outro, o de definir Calor, que não é uma energia própria de um corpo, a exemplo da Energia Interna. Sejam dois corpos A e B, sendo a temperatura de A maior que a temperatura de B. A energia em forma de calor não pode ficar no corpo $\mathrm{A}$, nem no corpo B. Logo não pode ter as propriedades do calórico. Essa energia térmica está em trânsito entre os corpos A e B. Agora, com o emprego do termo "energia térmica", pode-se falar em transformação de uma energia em outra. Como, por exemplo, do Calor em Trabalho, que é um dos objetos da Termodinâmica.

$\mathrm{Na}$ representação que se segue, a energia térmica está saindo de $\mathrm{A}$ e chegando em $\mathrm{B}$, devido ao fato da temperatura do corpo A ser maior que a temperatura do corpo B. A seta está indicando que a energia térmica está sendo transferida de A para B e o calor está simbolizado por uma barra vertical representando a energia definida na fronteira entre os corpos A e B.

A figura que se segue foi elaborada a partir da Figura 13.1 de Máximo e Alvarenga (1997) [13]. Entretanto, a seta nesta figura está re- 

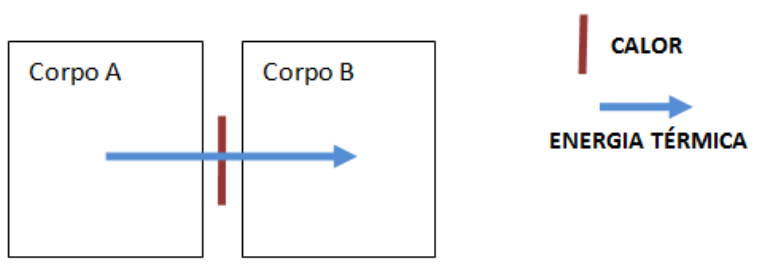

FIGURA 1: Texto da figura.

presentando a transferência de energia térmica, enquanto que na Figura 13.1 ela está representando o calor.

Finalizando, sob a nossa óptica, expressões como "Geração de Calor", "Transferência de Calor", "Troca de Calor", "Perda de Calor", "Retirada de Calor", "Corrente de Calor", "Propagação de Calor", "Condução de Calor", "Irradiação de Calor" e "Fluxo de Calor" carregam erros semânticos que comprometem a compreensão dessa grandeza. Os livros didáticos, que são indispensáveis ao aprendizado e à difusão do conhecimento, têm contribuído na disseminação e vulgarização de expressões inadequadas na definição do calor.

A cultura científica associada ao prestígio de cientistas como Fahrenheit, Carnot, Galileu, Lavoisier, Laplace, Fourier, Kelvin e Black contribuíram para a aceitação da teoria do calórico. Foi necessário que outra plêiade de cientistas desmistificassem o calórico e dessem um novo significado ao calor. Conde Rumford e Prescott Joule foram preponderantes nesse processo. Entretanto, devido ao uso contínuo de termos remanescentes da época em que a teoria do calórico era aceita, tais como "Calor Latente", "Calor Sensível" e "Condutibilidade Térmica", persistem como verdadeiros obstáculos epistemológicos na mudança conceitual do calor.

\section{CONCLUSÃO}

A teoria do calórico foi descartada de forma sistematizada nos idos do século XIX, mas a utilização de suas características mantém viva essa teoria, quando são atribuídas ao calor, em pleno século XXI, qualidades de uma função potencial.

Observa-se que o calor é normalmente definido como a energia que é transferida de um corpo para outro devido à diferença de temperatura entre os corpos. Essa transferência cessa quando é estabelecido o equilíbrio térmico. Entretanto, após o equilíbrio térmico, essa quantidade energia que foi transferida, que é usualmente denominada de calor, pode não ser constatada, pois, no corpo, essa energia pode sofrer uma transformação. Logo, podem ocorrer situações em que essa quantidade de energia, em forma de calor, pode não ser obtida na sua integralidade em função apenas da diferença de temperatura que o corpo sofreu ao trocar energia térmica. Entendemos que a energia em forma de calor só deve ser definida durante o processo de transferência. É neste sentido que entendemos que o verbo "transferir" não deve ser usado no tempo passado. Entendemos também que a energia atribuída ao calor deve ser renomeada para energia térmica, a partir do momento em que se encontra no lugar de origem ou destino, principalmente quando não se analisou a denominação que essa energia irá assumir. Entretanto, pode ser garantido que a sua origem é térmica, quando tal transferência estiver condicionada a uma diferença de temperatura.

Acreditamos que a cultura científica contribuiu para existência de obstáculos epistemológicos para que ainda sejam usados termos como "Geração", "Transferência", "Troca", "Perda", "Retirada", "Corrente", "Propagação", "Condução", "Irradiação" e "Fluxo" de Calor. Acreditamos também que uso de termos como Calor Latente, Calor Sensível e de Condutividade Térmica, plenamente aceitos pela linguagem científica, contribuem para a concepção de calor como característica do corpo, uma vez que para calcular o calor envolvido na transformação são inseridas em suas equações grandezas típicas do próprio corpo tais como sua massa, sua variação de temperatura, o Calor Latente de mudança de fase da substância e o Calor Específico da substância do corpo. É possível que essas expressões ainda agreguem resquícios do calórico. 
Entendemos que a definição de calor seja "a energia em transferência entre dois sistemas (ou corpos), devida exclusivamente à diferença de temperatura entre eles". Com isso, o calor só deverá existir na fronteira entre corpos ou sistemas e não dentro deles. Portanto, a definição do termo calor está precisando ser revista. Quando a troca de energia térmica envolver o sistema (ou corpo) e o meio exterior, a diferença de temperatura considerada será tomada no próprio sistema (ou corpo), ou seja, subtraindo a sua temperatura inicial da final. Por usar apenas grandezas do próprio corpo pode induzir a existência de um obstáculo.

Os livros didáticos pesquisados continuam tendo a sua relevância para o processo ensinoaprendizagem, contudo é preciso superar os erros conceituais apresentados na teoria do calor.
[1] G. Allard et al., História Geral das Ciências: A Ciência Moderna: Tomo II. O século XIII, vol. 3. São Paulo: Difusão Européia do Livro (1960).

[2] G. Allard et al., História Geral das Ciências: A Ciência Contemporânea: Tomo III. O século XIX, vol. 2. São Paulo: Difusão Européia do Livro (1967).

[3] M. Wilson, A Energia. Rio de Janeiro: Livraria José Olympio Editora (1967).

[4] J.M.F. Bassalo, A crônica do calor: Termometria. Revista de Ensino de Física 13, 135 (1986).

[5] J.M.F. Bassalo, A crônica do calor: Calorimetria. Revista Brasileira de Ensino de Física 14, (1) 29 (1992).

[6] R. Axt, M.E. Brükmann, O conceito de calor nos livros de ciências. Caderno Catarinense de Ensino de Física 6, (2) 128 (1989).

[7] D.K. Costa, M.J.V.C. Hülsendeger, Concepções de Alunos de Ensino Médio sobre o Estudo do Calor. In: IV Encontro IberoAmericano de Coletivos Escolares e Redes de Professores que Fazem Investigação na Escola, 2005. Lajeado: UNIVATES(2005).

[8] J.L. Cindra, O.P.B. Teixeira, Calor e temperatura e suas explicações por intermédio de um enfoque histórico. In: R.A. MATINS, L.A.C.P. MARTINS, C.C. SILVA, J.M.H. FERREIRA (Eds.), Filosofia e História da Ciência no Cone Sul: $3^{\circ}$ Encontro. Campinas: AFHIC (2004).

[9] E.M.R. Amaral, E.F. Mortimer, Uma Proposta de Perfil Conceitual para o Conceito de Calor. Revista Brasileira de Pesquisa em Educação em Ciências 1, (3) 5 (2001).

[10] J.J. Correia, L.D.R. Magalhães, L.S. Lima, Obstáculos Epistemológicos Envolvidos no Conceito de Calor. In: XXVI Encontro de
Físicos do Norte-Nordeste, CD, 2008. Recife (2008).

[11] G. Bachelard, A formação do espírito científico: contribuição para uma psicanálise do conhecimento. Rio de Janeiro: Contraponto (1996).

[12] D.A. Andrade, A importância dos obstáculos epistemológicos para o desenvolvimento da ciência: a contribuição de Gaston Bachelard. Pensar 9, 45 (2004).

[13] A. Máximo, B. Alvarenga, Curso de Física, vol. 2. São Paulo: Scipione Editora (1997).

[14] A. Gonçalves Filho, C. Toscano, Física e Realidade: física térmica e óptica, vol. 2. São Paulo: Scipione Editora (1997).

[15] Dalton, Física: Termodinâmica, Óptica, Ondas. Rio de Janeiro: Ao Livro Técnico (1979).

[16] C.S. Calçada, J.L. Sampaio, Termologia, Fluidomecânica e Análise Dimensional. São Paulo: Editora Atual (1998).

[17] D.N.S. Paraná, Física: Termologia, Óptica, Ondulatória, vol.2. São Paulo: Ática (1998).

[18] M. Alonso, E.J. Finn, Física - Um Curso Universitário. São Paulo: Edgard Blücher (1972).

[19] R.F.A. Bonjorno, J.R. Bonjorno, C.M. Ramos, Física: Termologia, Óptica Geométrica e Ondulatória. São Paulo: Editora FTD S.A. (1985).

[20] A.A. Chiquetto, M.J. Parada, Física. São Paulo: Scipione Editora (1986).

[21] E.C. Costa, Tomo I: Física Industrial. Termodinâmica - I Parte. Porto Alegre: Editora Globo (1971).

[22] E.C. Costa, Tomo I: Física Industrial. Termodinâmica - II Parte. Porto Alegre: Editora Globo (1971).

[23] L.D. Giudice Neto, Física, vol 2. São Paulo: Editora FTD S.A. (1980).

[24] J. Goldemberg, Física Geral e Experimental, 
vol. 1. São Paulo: Editora Nacional e Edusp (1970).

[25] GREF, Física 2: Física Térmica e Óptica. São Paulo: Edusp (2005).

[26] D. Halliday, R. Resnick, Física I, vol. 2. Rio de Janeiro: Livros Técnicos e Científicos (1977).

[27] H. Macedo, A.M. Luiz, Problemas de Termodinâmica Básica: Fúsica e Química. São Paulo: Edgard Blücher (1976).

[28] V.P. Moretto, Física em Módulos de Ensino: Óptica, Ondas e Calor. São Paulo: Ática (1982).

[29] H.M. Nussenzveig, Curso de Física Básica 2: Fluidos, Oscilações, Ondas e Calor. São Paulo: Edgard Blücher (2004).

[30] J.M. Oliveira, Termodinâmica. São Paulo: Editora Livraria da Física (2005).

[31] J. Orear, Física. Rio de Janeiro: Livros Técnicos e Científicos (1976).

[32] A.B. PÁDUA, C.G. Pádua, Uma Coletânea de Problemas. São Paulo: Editora Livraria da Física (2006).

[33] F. Ramalho Jr., G. Herskowiz, V. Scolfaro, Elementos de Física, vol. 2. São Paulo: Editora Moderna (1986).

[34] F. Ramalho Jr., N.G. Ferraro, P.A. Toledo Soares, Os Fundamentos da Física: Termologia, Óptica e Ondas, vol.2. São Paulo: Editora Moderna (1993).

[35] J.I.C. Santos, Conceitos de Física, vol. 2. São Paulo: Editora Ática (1986).

[36] F.W. Sears, Física I: Mecânica, Movimento Vibratório e Calor. Rio de Janeiro: Ao Livro Técnico (1966).

[37] F.W. Sears, G.L. Salinger, Termodinâmica, Teoria Cinética e Termodinâmica Estatística. Rio de Janeiro: Guanabara Dois (1979).

[38] F.W. Sears, M.W. Zemansky, Física: Calor,
Ondas e Ótica. Rio de Janeiro: Livros Técnicos e Científicos (1976).

[39] P.A. Tipler, Física, vol. 1. Rio de Janeiro: Guanabara Dois (1978).

[40] P.A. Toledo Soares, N.G. Ferraro, J.I.C. Santos, Aulas de Física 2: Hidrostática, Termologia, Óptica e Ondas. São Paulo: Atual Editora (1984).

[41] P.T. Ueno, I. Yamamoto, Estudos de Física: Termologia, Óptica e Ondas. São Paulo: Editora Moderna (1982).

[42] G.J. Wylen, R.E. Sonntag, Fundamentos da Termodinâmica Clássica. São Paulo: Edgard Blücher (1973).

[43] M.W. Zemansky, Calor e Termodinâmica. Rio de Janeiro: Guanabara Dois (1978).

[44] Professor de Física do Departamento de Ciências Exatas (DCE) da Universidade Estadual do Sudoeste da Bahia (UESB), doutor em Física Atômica e Molecular pela Universidade Federal de São Carlos (UFSCar), membro do grupo de pesquisa "Teorias do Ensino e da Aprendizagem das Ciências Experimentais e da Matemática", ligado ao MP, com a linha de pesquisa "Origem e Evolução dos Conceitos em Física".

[45] Professora de Políticas Educacionais do Departamento de Filosofia e Ciências Humanas (DFCH) da UESB, doutora em Educação pela Universidade Estadual de Campinas (Unicamp), Coordenadora Geral do Museu Pedagógico Casa Padre Palmeira (MP) e do grupo de pesquisa "História das Reformas Educacionais e Trajetórias Geracionais".

[46] Graduanda do Curso de Licenciatura em Física da UESB e bolsista de iniciação científica da FAPESB pelo MP. 